\title{
"And Slowly, the Integration and the Growing and the Learning": Nuanced Notions of Integration of Bhutanese Refugees in US Cities
}

\author{
Annie Taccolini Pannagio and Odessa Gonzalez Benson *i) \\ School of Social Work, University of Michigan, Ann Arbor, MI 48109, USA; annietacc@gmail.com \\ * Correspondence: odessagb@umich.edu
}

Received: 16 April 2019; Accepted: 6 June 2019; Published: 11 June 2019

\begin{abstract}
Policy related to refugee integration focuses on economic factors, while integration is not clearly operationalized nor is it being systematically measured and tracked in policy implementation. This study poses the question, how can local-level integration be conceptualized based on the perspectives of resettled refugees, to add nuance to policy. Using a case study approach with a nation-wide scale, data include 40 interviews and five focus groups with leaders of Bhutanese refugee-run organizations in 35 cities across the United States. Findings illustrate the importance of bonds, bridges and links in non-linear, relational integration. Findings also suggest that better access to services and resources is the responsibility of policy-makers and would lead to stronger bridges over time. This complicates existing policy and implies that resettlement programming should remain individualized and contextual from the ground level to the national level.
\end{abstract}

Keywords: two-way integration; resettled refugees; Bhutanese; resettlement policy

\section{Introduction}

Refugee integration is nebulously defined on the home page of the federal institution of refugee resettlement: "The Office of Refugee Resettlement (ORR) helps new populations maximize their potential in the United States by linking them to critical resources that assist them in becoming integrated members of American society" (US ORR 2019). According to the most recent government assessment of US resettlement policy, "Integration is also a part of ORR's mission and overall goal", and resettlement officials and practitioners "consider integration to be a central aspect of refugee resettlement” (US GAO 2012). ORR “aim(s) to prepare refugees for long-term integration into their communities" (US GAO 2012).

However, at local, on-the-ground levels of policy implementation, "integration" is not clearly operationalized nor is it systematically measured or tracked (US GAO 2012; Brick et al. 2010, p. 15). Non Governmental Organizations (NGOs) and service providers attributed the lack of measurement to having no definition of integration in federal policies that drive programming (US GAO 2012). 'Integration' exists as a concept in policy discourse on websites and in on-the-ground practice, but integration is not an explicit goal of the Refugee Act of 1980, the original refugee resettlement legislation in the United States. Instead, federal resettlement policy specifies self-sufficiency as a desired outcome; while the term 'integration' is not present (Refugee Act 1979). Self-sufficiency as a policy goal means that refugees' employment becomes the focus of frontline workers and practitioners in the field (Darrow 2015, 2018; Gonzalez Benson and Taccolini Panaggio 2019).

The ambiguous policy aim of 'integration' combines with the official policy aim of self-sufficiency, defined as non-dependence on public assistance via employment. Integration then becomes focused on financial issues in both practice and research. In the recent report on integration by the 
Migration Policy Institute (MPI), the measures of integration were exclusively related to economic well-being: on employment, unemployment and underemployment rates, income, and public benefits (MPI 2015). Language abilities and education were also measured but within the context of employment (MPI 2015).

While economic self-sufficiency measures one aspect of integration, it is not all-encompassing and fails to account for complexities related to resettlement and integration. Additionally, this measure may be more tailored to the federal level of programming, without understanding of how local communities integrate new arrivals. The prioritization of economics in resettlement policy may have been necessary to gain political support for acommunity (Gonzalez Benson 2016), but institutional economic priorities may be at odds with the daily lives of particular people placed in particular places. It is unclear how integration in communities and cities compares to definitions of integration that come from policy. This study examines local-level integration from the perspective of resettled refugees, using a case study approach and drawing from theoretical frameworks. The aim is to help fill that gap in refugee policy research in the United States.

This study distinguished between how native-born persons may integrate with new environments throughout their lives. Migrant integration is not examined from the perspective of economic well-being or marginalization from a certain community, but rather, from a broader question of what it means to become part of a new sociocultural space; and how social policy acknowledges and participates in that process.

As mentioned, policy around refugee integration has primarily been preoccupied with economic considerations. This study's main focus is integration at the level of individual refugee experience. By looking at the lives impacted by policy, we can analyze whether that policy is successful or not, and whether it is applied consistently. By examining resettled Bhutanese refugees in the United States, this study compares policy-based notions of integration with ones that are nuanced and evolving, like refugees themselves. The study examines perspectives of Bhutanese refugees as case study, as researchers have positionalities and experience working with this population. Research inquiry focuses upon 'how integration can be conceptualized using Bhutanese refugees' perspectives'. We draw from notions of 'bonds, bridges and links', detailed below, for that conceptualization. Our findings suggest that there is no constant definition of integration, but that the economics-based definitions in resettlement policy are not always what are reflected in the experiences of becoming part of a community. Flexible policy is therefore necessary. Leaders of refugee organizations were consulted for this study, and our conclusion references their experiences and their suggestions. Bhutanese refugees are deemed an effective case study for two reasons: they are present throughout the United States is dispersed, and they are known for their participation in community organizing both in cities and in refugee camps (discussed further below).

\section{Bonds, Bridges, and Links}

Other scholars have challenged an economic emphasis on integration and viewed it instead as a 'two-way' and 'non-linear' experience (Ager and Strang 2008; Atfield et al. 2007; Vrecer 2007). Integration does not assimilate one group into the whole of another group but rather comingles two different perspectives and ways of life to create symbiotic and diverse sociocultural ecosystems (Vrecer 2010). (Ager and Strang 2008) state that the perspectives of both newcomer community and existing society are necessary to avoid the faulty idea of integration as "'insertion' of one group amidst another". Refugees perceive what it means to be in a new nation, and native-born residents consider what it means to welcome new members into a preexisting society.

The 'two-way' approach to research evolved in response to perspectives that discussed integration in a more linear manner. Such research only considered how well refugees acculturated into broader society (Ager and Strang 2008; Malkki 1992; Han 2013; Phillimore 2010) and prioritized longevity of housing and employment (Birgier et al. 2016). By conceptualizing integration as two-way and 
non-linear, the 'receiving community' is implicated in refugee integration and resettlement with equal weight as the 'entering community'.

Integration from a mutual partnership or non-linear lens is comprised of three elements: bonds, bridges, and links (Boateng 2010; Strang and Ager 2010). Bridges and links refer to social and cultural relationships that extend beyond the refugee community; bonds refer to relationships within the refugee community. Each element plays a distinct and important role in the integration process (Martone et al. 2014; Cheung and Phillimore 2017), as detailed in our discussion and conclusion. Integration in the extended community is necessary for upward mobility (Cheung and Phillimore 2017). Social capital, or the value associated with relationships in social settings, is important in refugees' sociocultural integration (Boateng 2010; Sime and Fox 2014), although a critique of social capital is also necessary to account for the ways through which social capital for resource-poor communities can also constrain them to within-group social networks (Zetter et al. 2005).

Much research has considered integration as two-way and non-linear. Ager's idea of integration was more intentional in including qualitative narratives from refugees themselves (Ager and Strang 2008; Strang and Ager 2010; Vrecer 2010; Platts-Fowler and Robinson 2015). However, such discussions are largely missing within discussions of refugee resettlement in the United States.

Within the United States, little has been published that specifically speaks to the social and cultural aspects of refugee integration (Tyson 2017). Though there is a rich body of US literature on integration, assimilation, and adjustment (Massey 1981), integration has been largely examined as immigrant integration. Few studies consider refugees, in particular, as a subset of immigrant populations.

The bulk of studies on refugee resettlement in the United States is concerned with policy relevance (Bakewell 2008) and has focused on economic considerations or employment (MPI 2015; Darrow 2015), given that self-sufficiency is the aim of US resettlement policy. Darrow (2015), Smith (2013), and Gonzalez Benson and Taccolini Panaggio (2019) analyze the emphasis on employment by state-contracted refugee-serving organizations. Nevertheless, such studies concern themselves with the economic aspects of integration. Moreover, these studies do not focus on 'integration' —only imply it-when discussing economic considerations. Similarly, other US-based studies also only indirectly examine integration via related topics, such as food (Patil et al. 2010), housing, healthcare, education (Kenny and Lockwood-Kenny 2011), health, and mental health (Birman and Tran 2008). Other studies focus on earlier refugee groups, such as Hmong and Bosnian refugees (Duchon 1997; Grigoleit 2006; Franz 2003), and others focus on native-born perspectives rather than those of refugees themselves (Smith 2013). "There is not much known about integration" (of refugees in the United States), concluded the most recent report commissioned by the US government for examining resettlement. This study aims to address the gap in considering social and cultural aspects of integration.

\section{Methods}

To examine notions of refugee integration at local levels, this paper uses a case study approach with a national scope, focusing on organizational perspectives from key members and leaders of Bhutanese refugee community organizations (RCOs) in cities across the United States.

Case study: Bhutanese refugees. In the late 1980s, the Buddhist-majority government of Bhutan implemented policies that suppressed the culture, language, and belief system of the Nepali ethnic minority group, resorting to violence to implement policy (Rizal 2004). More than 100,000 people fled religious and ethnic persecution in Bhutan and sought refuge in refugee camps in Nepal for two decades. Resettlement began in 2008, and over 80,000 Bhutanese refugees have resettled in hundreds of cities across the United States.

Data and analysis. Data are 40 interviews and five focus groups with leaders of Bhutanese refugee organizations. These organizations include 35 RCOs based in the 35 cities in 30 states where Bhutanese refugees were placed by the US government over 10 years of resettlement. Please see Appendix A for the list of cities and states. The cities where the RCOs included in this study were located include cities in the west, south, northeast, and Mid West regions; large, midsize, and small size cities; long-established 
resettlement cities and emerging cities of resettlement; and cities that may reflect different political leanings towards refugees (and immigrants). The national scope of data enabled the study to examine concepts of integration across various cities and locales. As this study examines only one refugee group, ethnicity was not a factor that needed to be considered. The specific analysis is part of larger research project on the organizational life of Bhutanese refugees.

This study used snowball recruitment, as is common for trying to engage elusive communities, such as refugees (Atkinson and Flint 2001); four Bhutanese RCO leaders initiated contact by identifying participants in their networks. The 40 interviewees and focus group participants were leaders or key members of Bhutanese RCOs. All interviewees and focus group participants were male, spoke English, and had some employment and/or educational experience, and thus had relatively high socioeconomic status (SES). Such characteristics are generally representative of organizational leaders of Bhutanese refugee communities in the United States. A research design that focuses on organizational leaders has advantages and disadvantages. On the one hand, such organizational leaders have access to insights, values, and experiences of community members and are thus able to convey insights from the community. On the other hand, their ideas and experiences only indirectly reflect ideas of individuals and families in the community. That is to say, their organizational perspective may nevertheless privilege their own perspectives as leaders and their own SES status. This limitation justifies further studies that directly capture additional perspectives of refugees, particularly those with lower SES.

Interviews, focus groups, research consultations, and other aspects of research planning were conducted in English, as most Bhutanese refugees who are organizational leaders speak English sufficiently. As such, there was no translation process involved in this study; English language competency was, in effect, a criterion for selecting participants. Nevertheless, transcribed interviews (used as data in this paper) were revised for grammar and comprehension.

Sampling in this study was limited to particular areas and may not be representative of a larger region. Certain states were not included in the study due to recruitment challenges; there were few Bhutanese refugees in those states, and most had relocated to other cities by the time the data was collected. Locating participants in those states and cities was challenging. Furthermore, it was determined that data saturation was reached, and continued data collection for more states was not needed (Guest et al. 2006) had been reached, and recruitment was curtailed. Systematic analysis of city-level and state-level variation were not conducted for this study, and is a limitation. Future studies could explore how perspective — at both the organizational and individual level-may vary depending on location.

The interviews were based on the Guide for Organizational Profile Interviews (Anucha et al. 2006), used for examining refugee organizations (Lacroix et al. 2015). Focus groups expanded on concepts discussed in interviews. The fifth focus group was conducted for member checking (Kidd and Parshall 2000) to discuss and elaborate on initial findings. Participants in the five focus groups were leaders or key members of the five RCOs based in different cities. The first focus group was conducted in the city with the largest number of Bhutanese refugees at the time of data collection. The subsequent four focus groups were based on snowball sampling from these networks. The first author conducted the fifth focus group in 2018 as a second phase of data collection. In 2015, the second author collected primary data used in this study. The first author has worked in the field of refugee resettlement for two years and maintains a relationship with Bhutanese RCOs in one city. The second author, meanwhile, for more than a decade, has worked with Bhutanese RCOs in five US cities, and continues to conduct research with these groups today.

Interviews and focus groups were audio recorded and transcribed, and analyzed using Atlas.ti, which allows for management and analysis of qualitative data. Analysis involved open coding. The second author coded for concepts specified in the Interview Guide as well as other evident concepts. Early on, themes related to social and cultural integration emerged. Second-level coding, conducted by the first author, used an abductive approach (Timmermans and Tavory 2012). Analysis incorporated empirical data and existing theoretical frameworks on integration. 


\section{Results}

The results of the study are sorted into themes, based on an analysis of bonds, bridges, and links. This approach valorizes nuanced definitions of integration as described by participants.

"And slowly, the integration and the growing and the learning, and now I am ok." US refugee resettlement policy primarily focuses on survival needs and employment. Yet, Bhutanese refugees expressed that there is more to their lives in the United States than economic survival. As one participant said,

"You know, the US government has provided us with food, with jobs, with everything that are the basic needs. But that's not all that we need. We need other cultural things, our identities are there, other things that are there: cultural identities, or language, or culture".

The participant refers to "government" at the federal level and in the context of resources provided to all newly arrived refugees upon entering the United States. However, the second part of the participant's quote refers to integration at the local level-where culture, language, and identity play out. This participant's quote succinctly reflects on the disconnection between national policy and local-level integration-what we refer to below as bridges, links, and bonds.

\subsection{Bridges as Individuals, Families, Communities: "Striking the Balance between"}

Gaps between the Bhutanese refugee populations and the larger community can be addressed through bridges - interpersonal connections with people outside one's cultural group. Bridges foster a sense of connectedness and acceptance between people of a region, city, or workplace (Strang and Ager 2010).

Local community events. Community events were suggested as a way to share culture with outside Bhutanese refugee populations. Many participants offered examples of what this process could look like on the local level. One participant shared that in his midwestern city,

"Once or twice a year, there is to be a show, where American people and other immigrants, and Bhutanese and immigrants from other countries, would do the programs together. So that could relate to integration among Bhutanese people and people from other countries including Americans".

Participants often spoke of events like this. Local community events were tangible ways that cultural practices could be both preserved and shared. Another interviewee from a southern city said, "We are organizing multicultural festivals. We invited different people. There was English song being sung by a white person, there was a Spanish song, some Spanish people came, and in Bhutanese also". These events helped local leaders better understand Bhutanese refugees and their needs: "The Mayor was very cooperative, even the city councilmen, by attending the cultural event". Other studies have also found that social events are key to cultural exchange. Studies show that when events, such as cultural expositions and music shows (Lewis 2010), are hosted by refugees and open to the larger community, both parties perceive integration positively (Lewis 2010; Ulack 2013).

Individual and families. Many participants spoke of people who had been particularly helpful and meaningful during the integration process. One RCO leader from a midwestern city shared the story of meeting an American professor in a park. They met because of the professor's dog, but as they talked, they formed a bond that remained with this participant and her family for years. She said of the professor and her family,

"The best part was that [the professor] was happy that my mother, who spoke no English at all, because the professor was helping us every day with that, my mother, she started to speak English, she started going to a job. They helped us find jobs for my mother and they found after school program for me and my brother to go to ... they did pretty much all that for a couple of years and I'll never forget". 
For another RCO leader from a northwestern city (Rhode Island), integration is successful when, for example,

"[People] from the American community come to a Nepali family, sit together for two or three hours, discuss. If there is a language barrier, they will try to have some interpreter. And see how the Nepali family would know how to raise a child in America and the American mom will know how to raise a child in Nepal. So they will know this is how the culture will get exchange and people will learn".

Relationships like this bridged cultural gaps, and created connections. Another participant shared that his wife went to their neighbor's apartment after her husband lost his job, "and she was crying with her and said 'my husband he lose his job and we have to pay. It is day 27 and we have to pay the rent and we don't have money to pay the rent'". The neighbor helped them talk to their landlord and look for new work. This relationship has remained over years, and this participant identifies the neighbor as a key player in their early days in the United States. In this case, the relationship was a connection to the extended community, and a resource during difficult times.

\subsection{Links as Connections to Persons and Institutions: "US Government or Resettlement Agencies Do Not Focus on The Cultural Practices"}

This study also shows how public resources and opportunities help narrow the integration gap. The relationship between a person and their social system can be thought of as links (Ager and Strang 2008), or an individual's connections to institutions and resources (Boateng 2010). Links are strengthened through access to social services and, therefore, equal access to services and programs is necessary for integration of resettled refugees (Strang and Ager 2010; Platts-Fowler and Robinson 2015).

Many participants in our study, however, lacked links. At the institutional level, the cultural values and norms of refugees were not considered. One participant said succinctly that the "US government and resettlement agencies do not focus on the cultural practices". In a midwestern city, one interviewee acknowledged, "[the resettlement agency] is running that class and another job class. but what the organization is providing is not adequate". Another shared, "how can we tell the US government [about our culture]? Still they do not help us, they do not ask". Participants recognized that the broader US systems were not intended to help refugees beyond the basic initial resettlement process. Here, the participant refers to "government" as state-level leadership. One participant had suggested that his RCO presented ideas for better local-level integration programs to state senators or to their governor. Such policy decisions are ultimately federally based, though state and city governments can choose to provide supplementary supports for resettled refugees.

Study participants tended to agree that their collectives had few resources and were often "undermined" by institutional actors, a term that one participant from a northeastern city also used. "I mean, we were very weak in terms of relationships because we were new", that participant shared. Several participants discussed the challenges of trying to form partnerships with governmental agencies and established organizations. Another interviewee said, "I met with the city development authority, with a senator, with a state representative, but did not receive direct help".

The bureaucratic process of pursuing American citizenship was also discussed. Being an American citizen was a point of pride for many participants, making the process even more disheartening when it was un-navigable at local levels. For one participant from a southern city, "national integration" meant being "loyal to the US government and the Constitution"; another participant in a different southern city shared that Bhutanese refugees are "people (who) want to work as American citizens" to "support the law of the land". Indeed, citizenship was a critical institution for integration and belonging, as expressed by one participant:

"One thing that is good in life is now I have become a citizen. Before I was a citizen here, I did not [have] a symbol of any country. Because before in Bhutan, our citizenship was taken. 
In Nepal, we just stayed there without citizenship. Then we came here, we got citizenship and that's good for me".

\subsection{Bonds as Culture and Identity: "Integration Is Not to Lose Everything"}

Bridges and links are key components to integration according to Bhutanese refugee organizational leaders in our study. These connections to the larger community did not translate into a weakening of within-group connections or bonds. As one participant said, "integration is not to lose everything". Integration, he explained, was not about sacrificing deeply rooted parts of one's life, but rather, an opportunity to grow and share with people of all backgrounds.

"Bonds" refers to family connections, networks, and ethnic communities that allow people to "share cultural practices and maintain familiar practices of relationships" throughout the process of integration (Ager and Strang 2008; Strang and Ager 2010). Bonds function as protective factors, especially for newly arrived people adjusting to new routines, such as determining where to buy certain foods and where to worship (Ulack 2013). Sharing mutual experiences was key to the processes of adjustment and familiarization.

Study participants formed bonds through sharing resources, celebrating culture, and building community. Integration that allows groups to maintain individual identity while living in a new place is important. One participant shared, "We want our people to embrace the good things we have... don't forget, we value our elders, we value our association with our parents. Don't ever, you know, disregard those things". One way to celebrate cultural identity was through events focusing on food, language, dance, music, and other cultural elements. "Every year, we organize cultural activities", one person said. Another participant stated, "Especially kids-we are targeting them [with these activities]; they should know our culture, they should know our language". For one participant, forming a Bhutanese RCO was a way to support others and to facilitate cultural practice: "The purpose [of our organization] was basically to keep everything and everyone in the loop. I mean staying together, helping each other, maintaining the culture, even maintaining the language, the mother tongue".

Bonds assist integration precisely through the sharing a collective journey. Lessons can be learned by forming bonds with those who share a sociocultural background and are also attempting to become part of a new environment. By participating in cultural events and encouraging such bonds, leaders in the community support the integration process in an intimate and effective way (Ager and Strang 2008). As one participant noted, "and slowly, the integration and the growing and the learning and now I am ok".

\section{Discussion}

While federal policy defines integration as self-sufficiency, refugee narratives illustrate nuanced notions of integration at local levels: bridging, linking, and bonding with individuals, families, and communities. These local-level manifestations of integration are missing in federal resettlement policy, which fixates on economics. Bridging also implicates the broader community-the host or receiving community-in the integration process. Focusing on the relational nature of integration offers a more holistic approach to the resettlement experience for both existing and new communities. However, this study illustrates a vulnerability in connections that link the local level with the institutional level. Like studies about particularly marginalized refugees (Boateng 2010), our findings show weak connections between the sociocultural aspects of integration and public resources, and inadequate access to culturally meaningful institutional supports. Conclusions may differ by state or city, as determined by local laws, size of NGOs, or community outreach practices. Other studies point to variations in holistic integration processes in state and local governments; but this study does not compare these differences. Links, as defined by Ager and Strang (2008), are not different in local, state, or national relationships; as such, there is room in the field of refugee studies for research that considers possible differences.

Patterns in the data analyzed here confirm the categorization of bonds, bridges, and links. Participant discussions about relationships fit into those three categories, as they discussed integration. 
Refugees spoke of bonds, bridges, and links without being prompted by researchers. As a whole, participants spoke most of bonds-in family life, celebrations, shared meals, and mutual experiences.

Trends in data showed that relationships that fit in the category of bridges were less common, more likely to be connected to difficult circumstances (i.e., asking a neighbor for assistance), and more often required work or planning (i.e., culture-sharing events). When these relationships were built, however, they proved to be more deeply influential in the integration experience than bonds. While bonds tended to keep individuals connected and content in their routines, bridges moved them into a new understanding of life and a broader knowledge of their new country.

Participant stories about links consistently included negative experiences. Interviewees rarely had positive experiences with the social systems they interacted with during resettlement. These organizations left them struggling, unable to reach a full sense of self-sufficiency, even when they were self-sufficient economically.

\section{Conclusions}

While participants of this study shared stories of their community activities and neighborly relationships, they offered little about bureaucratic support. From a social policy perspective, these non-responses suggest ineffective integration for refugees at the institutional level. Some participants made suggestions about how their communities could be better supported: longer periods of case management, and more time and autonomy to select employment and housing, and more support in building their community centers to facilitate bonds during the integration process. Many refugees seem willing to offer ideas about how the system could work more in their favor, both economically and otherwise.

Taking these suggestions and stories into consideration, we suggest that link relationships could lay a strong foundation for more bridges. According to our data, links are the weakest factor in sustainable integration, according to interviews. Links can create bridges if, through the process of connecting new refugees with community members who are incentivized to help refugees with day-to-day needs. Rather than being a fixed period, the length of case management could be determined by a moment when refugees are properly prepared for autonomous life in the United States. Sociocultural success ('bonds, bridges, and links') could by measured by practices that offer fuller understanding of integration, much like economic success among refugees is currently measured as economic integration. Such measures would allow comparing outcomes by type of program, population, context and time period. This would facilitate not only accountability and effectiveness but also issues of social justice.

These findings provide a US-based application of the two-way, non-linear, and sociocultural concept of integration, used predominantly in European and in global contexts (Ager and Strang 2008). This more robust understanding of integration contradicts current US policy focus, which reduces the needs of entire refugee populations to one economic goal. The participants in this study come from various cities in the United States, and the themes of discussion with participants were influenced by the different cities. This perspective aids both policy makers and community builders in challenging the systems involved in integration. Many participants expressed that the more nuanced and personal aspects of their lives were less valorized than aspects that led to better and faster employment. Instead, refugee resettlement should reflect the permanence and complexity of being in a new space. This study suggests that US policy could better address the needs of refugee populations as they manifest at local levels and evolve through the various phases of resettlement.

While national policy provides standards and mandates for resettlement services, state-level governments are better qualified to determine more specific programming (i.e., private or public administration and public-private partnerships). State governments can also add services by using state funds and by seeking discretionary funding from the national government and private sources. Moreover, cities and private/nonprofit resettlement agencies (that implement federal policy) can supplement services for refugees to aid integration at local levels. Localized policy would result in measurements that evolve with changes as experienced by refugees over time as well. Public programs 
that invest in refugee communities at all levels, including in sociocultural elements could help improve not only employment rates, but well-being for both sides of the two-way process.

Author Contributions: A.T.P. conducted research conceptualization, writing, and analyses. O.G.B. conducted data collection and assisted with analysis and writing.

Funding: Fahs Beck Fund for Research.

Acknowledgments: The authors thank the Bhutanese community for participation, guidance and support for this study.

Conflicts of Interest: The authors declare no conflict of interest.

\section{Appendix A}

List of 35 cities included in study, alphabetically listed by state:

Phoenix, Arizona; Tucson, Arizona; Sacramento, California; Colorado Springs, Colorado; Jacksonville, Florida; Atlanta, Georgia; Boise, Idaho; Moline, Illinois; Kansas City, Kansas; Louisville, Kentucky; Baltimore, Maryland; Lansing, Michigan; St Paul, Minnesota; Las Vegas, Nevada; Concord, New Hampshire; Buffalo, New York; Syracuse, New York; Charlotte, North Carolina; Fargo, North Dakota; Akron, Ohio; Cincinnati, Ohio; Columbus, Ohio; Portland, Oregon; Harrisburg, Pennsylvania; Pittsburgh, Pennsylvania; Providence, Rhode Island; Abilene, Texas; Dallas, Texas; San Antonio, Texas; Seattle, Washington; Burlington, Vermont.

\section{References}

Ager, Alastair, and Alison Strang. 2008. Understanding Integration: A Conceptual Framework. Journal of Refugee Studies 21: 166-91. [CrossRef]

Anucha, Uzo, Nombuso S. Dlamini, Miu Chung Yan, and Lisa Smylie. 2006. Social Capital and the Welfare of Immigrant Women: A Multi-Level Study of Four Ethnic Communities in Windsor. Ottawa: Status of Women in Canada.

Atfield, Gaby, Kavita Brahmbhatt, and Therese O'Toole. 2007. Refugees' Experience of Integration. Vancouver: Refugee Council.

Atkinson, Rowland, and John Flint. 2001. Accessing hidden and hard-to-reach populations: Snowball research strategies. Social Research Update 33: 1-4.

Bakewell, Oliver. 2008. Research beyond the Categories: The Importance of Policy Irrelevant Research into Forced Migration. Journal of Refugee Studies 21: 432-53. [CrossRef]

Birgier, Debora Pricila, Christer Lundh, Yitchak Haberfeld, and Erik Elldér. 2016. Self-Selection and Host Country Context in the Economic Assimilation of Political Refugees in the United States, Sweden, and Israel. International Migration Review. [CrossRef]

Birman, Dina, and Nellie Tran. 2008. Psychological Distress and Adjustment of Vietnamese Refugees in the United States: Association with Pre- and Postmigration Factors. American Journal of Orthopsychiatry 78: 109-20. [CrossRef] [PubMed]

Boateng, Alice. 2010. Survival Voices: Social Capital and the Well-Being of Liberian Refugee Women in Ghana. Journal of Immigrant E Refugee Studies 8: 386-408.

Brick, Kate, Amy Cushing-Savvi, Samia Elshafie, Alan Krill, M. McGlynn Scanlon, and Marianne Stone. 2010. Refugee Resettlement in the United States: An Examination of Challenges and Proposed Solutions. New York: Columbia University School of International and Public Affairs.

Cheung, Sin Yi, and Jenny Phillimore. 2017. Gender and Refugee Integration: A Quantitative Analysis of Integration and Social Policy Outcomes. Journal of Social Policy 46: 211-30. [CrossRef]

Darrow, Jessica H. 2015. Getting Refugees to Work: A Street-level Perspective of Refugee Resettlement Policy. Refugee Survey Quarterly 34: 78-106. [CrossRef]

Darrow, Jessica H. 2018. Administrative Indentureship and Administrative Inclusion: Structured Limits and Potential Opportunities for Refugee Client Inclusion in Resettlement Policy Implementation. Social Service Review 92: 36-68. [CrossRef]

Duchon, D. A. 1997. Home Is Where You Make It: Hmong Refugees in Georgia. Urban Anthropology 26: 71-92. 
Franz, Barbara. 2003. Transplanted or Uprooted? Integration Efforts of Bosnian Refugees Based Upon Gender, Class and Ethnic Differences in New York City and Vienna. The European Journal of Women's Studies 10: 135-57. [CrossRef]

Gonzalez Benson, Odessa. 2016. Refugee Resettlement Policy in an Age of Neoliberalization: A Policy Discourse Analysis of the Refugee Act of 1980. Social Service Review 90: 515-49. [CrossRef]

Gonzalez Benson, Odessa, and Annie Taccolini Panaggio. 2019. ‘Work Is Worship' in Refugee Policy: Diminution, Deindividualization, and Valuation in Policy Implementation. Social Service Review 93: 26-54. [CrossRef]

Grigoleit, Grit. 2006. Coming Home? The Integration of Hmong Refugees from Wat Tham Krabok, Thailand, into American Society. Hmong Studies Journal 7: 1.

Guest, Greg, Arwen Bunce, and Laura Johnson. 2006. How many interviews are enough? An experiment with data saturation and variability. Field Methods 18: 59-82. [CrossRef]

Han, Xiaorong. 2013. Exiled to the Ancestral Land: The Resettlement, Stratification and Assimilation of the Refugees from Vietnam in China. International Journal of Asian Studies 10: 25-46. [CrossRef]

Kenny, Paul, and Kate Lockwood-Kenny. 2011. A Mixed Blessing: Karen Resettlement to the United States. Journal of Refugee Studies 24: 217-38. [CrossRef]

Kidd, Pamela S., and Mark B. Parshall. 2000. Getting the focus and the group: Enhancing analytical rigor in focus group research. Qualitative Health Research 10: 293-308. [CrossRef] [PubMed]

Lacroix, Marie, Michael Baffoe, and Marilena Liguori. 2015. Refugee Community Organizations in Canada: The Margins to Mainstream? A Challenge and Opportunity for Social Workers. International Journal of Social Welfare 24: 62-72. [CrossRef]

Lewis, Hannah. 2010. Community Moments: Integration and Transnationalism at Refugee Parties and Events. Journal of Refugee Studies 23: 571-88. [CrossRef]

Malkki, Liisa. 1992. National Geographic: The Rooting of Peoples and the Territorialization of National Identity among Scholars and Refugees. Cultural Anthropology 7: 24-44. [CrossRef]

Martone, Jessica, Danielle Zimmerman, Maria Vidal de Haymes, and Lois Lorentzen. 2014. Immigrant Integration through Mediating Social Institutions: Issues and Strategies. Journal of Community Practice 22: 299-323. [CrossRef]

Massey, Douglas S. 1981. Dimensions of the New Immigration to the United States and the Prospects for Assimilation. Annual Review of Sociology 7: 57-85. [CrossRef] [PubMed]

Migration Policy Institute. 2015. The Integration Outcomes of US Refugees: Successes and Challenges. Washington: National Center on Immigration Policy.

Patil, Crystal L., Molly McGown, Perpetue Djona Nahayo, and Craig Hadley. 2010. Forced Migration: Complexities in Food and Health for Refugees Resettled in the United States. NAPA Bulletin 34: 141-60. [CrossRef]

Phillimore, Jenny. 2010. Refugees, Acculturation Strategies, Stress and Integration. Journal of Social Policy 40: 575-93. [CrossRef]

Platts-Fowler, Deborah, and David Robinson. 2015. A Place for Integration: Refugee Experiences in Two English Cities. Population, Space and Place 21: 476-91. [CrossRef]

Refugee Act. 1979. Refugee Act of 1979, S 643: Hearing before the Committee on the Judiciary U.S. Senate; Washington: U.S. Govt. Print. Off.

Rizal, Dhurba. 2004. The Unknown Refugee Crisis: Expulsion of the Ethnic Lhotsampa from Bhutan. Asian Ethnicity 5: 151-77. [CrossRef]

Sime, Daniela, and Rachael Fox. 2014. Migrant Children, Social Capital and Access to Services Post-Migration. Children $\mathcal{E}$ Society 29: 524-34.

Smith, Yda J. 2013. Resettlement of Somali Bantu Refugees in an Era of Economic Globalization. Journal of Refugee Studies 26: 477-94. [CrossRef]

Strang, Alison, and Alastair Ager. 2010. Refugee Integration: Emerging Trends and Remaining Agendas. Journal of Refugee Studies 23: 589-610. [CrossRef]

Timmermans, Stefan, and Iddo Tavory. 2012. Theory Construction in Qualitative Research: From Grounded Theory to Abductive Analysis. Sociological Theory 30: 167-86. [CrossRef]

Tyson, Catherine. 2017. Towards a New Framework of Integration in the US. Forced Migration Review 54.

Ulack, Christopher Joseph. 2013. 'Starting from Below Zero': Iraqi Refugee Resettlement and Integration in the United States and Austin, Texas. Austin: The University of Texas at Austin, pp. 146-53. 
U.S. Government Accountability Office (GAO). 2012. Greater Consultation with Community Stakeholders Could Strengthen Program; Washington: Government Printing Office.

U.S. Office of Refugee Resettlement. 2019. Available online: https://www.acf.hhs.gov/orr (accessed on 1 April 2019).

Vrecer, Natalija. 2007. Integration as a Human Right: Forced Migrants from Bosnia-Herzegovina in Slovenia. Ljubljana: Scientific Research Centre of the Academy of Arts and Sciences and Slovenian Institute for Adult Education. Vrecer, Natalija. 2010. Living in Limbo: Integration of Forced Migrants from Bosnia and Herzegovina in Slovenia. Journal of Refugee Studies 23: 484-502. [CrossRef]

Zetter, Roger, David Griffiths, and Nando Sigona. 2005. Social Capital or Social Exclusion? The Impact of Asylum-Seeker Dispersal on UK Refugee Community Organizations. Community Development Journal 40: 169-81. [CrossRef]

(C) 2019 by the authors. Licensee MDPI, Basel, Switzerland. This article is an open access article distributed under the terms and conditions of the Creative Commons Attribution (CC BY) license (http://creativecommons.org/licenses/by/4.0/). 